\title{
Renovação Carismática Católica e Política: Relações, interferências e tensões
}

Rodrigo Portella

\section{Resumo}

A comunicação tem como objetivo apresentar as interações entre a Renovação Carismática Católica (RCC) e o campo da política, considerado amplamente. Assim, pretendemos analisar como a RCC vê e interpreta o campo da política, e como ela opera em tal campo. Pleiteia a presente comunicação verificar os imaginários teológicos e religiosos que permeiam o RCC e que justificam suas ações de intervenção no campo da política. A comunicação apresenta, a este respeito, tanto o discurso oficial da RCC, representado pela Secretaria Fé e Política, como os discursos carismáticos que estão para além da voz oficial do Movimento. De uma forma particular, pretende-se ilustrar a relação entre RCC e política não só em nível histórico e teológico, mas também revelando a intervenção que o Movimento, nas últimas eleições presidenciais de 2010, teve sobre o pleito eleitoral.

Palavras-chave: Movimento Carismático Católico; campo político; imaginário. 


\begin{abstract}
The Communication aims to present the interactions between the Catholic Charismatic Renewal (RCC) and the field of politics, widely regarded. Thus, we intend to analyze how the RCC sees and interprets the field of politics, and how it operates in this field. Debate this communication to verify the imaginary theological and religious that permeate the RCC and justify their actions to intervene in politics. The communication in this regard, both the official discourse of the RCC Secretariat represented by the Faith and Politics, as the charismatic speeches that are beyond the official voice of the Movement. In a particular way, it is intended to illustrate the relationship between RCC and politics not only in historical and theological level, but also revealing that the intervention motion, the last presidential elections of 2010 had on the polls.
\end{abstract}

Keywords: Catholic Charismatic Movement, the political field; imaginary.

\title{
Introdução
}

Penso que, para a reflexão que aqui é proposta, é dispensável antepor a ela algum histórico geral da Renovação Carismática Católica (RCC, adiante) e de suas ênfases doutrinárias. Antes de adentrar ao tema desta reflexão, porém, cabe uma advertência: a RCC, assim como a Igreja Católica em suas múltiplas dimensões, não perfaz um rosto único, mas é plural em seus variados grupos, membros e lideranças. Entretanto, mesmo em meio a tal pluralidade, existem idéias-força que, de uma maneira ou de outra, alinhavam um rosto básico do movimento, inclusive em suas inserções políticas.

\section{Referências básicas na RCC em sua relação com o campo político}

A RCC tem, tradicionalmente, na classe média urbana seu principal público e formador de opinião, ainda que, a partir da década de 1990, tenha a RCC alastrado seu trabalho e visibilidade junto a meios populares. Contudo, o foco ao redor do qual gira a RCC, sua principal referência, é ainda definido por certo ethos encontrado em uma classe média urbana católica de tendência mais conservadora quanto aos valores morais e doutrinas religiosas. Entretanto, a visão religiosa de mundo sustentada pela RCC talvez tenha mais afinidade eletiva com um espectro não racional e pré-moderno, estruturando um mundo 
encantado, mágico e emotivo que aponta certa falta de racionalização de suas práticas e ideários religiosos ${ }^{1}$, apesar de que a via de acesso a estas práticas $\mathrm{e}$ ideários seja moderna, de escolha reflexiva.

A partir deste básico mapa, poderíamos aventar que o ethos sociopolítico na $\mathrm{RCC}$, grosso modo, tenderia a refletir uma postura mais individualista, típica de determinada espiritualidade católica de antanho e de valores das classes médias urbanas (e, de certa forma, também devedora da modernidade): a noção de que é necessário antes santificar o ser humano, sendo a "santificação" da sociedade decorrência natural da santificação humana. Esta é a idéia-força. Como já definira nos anos 70 uma autoridade internacional da RCC, Caetano Tillesse, em livro que analisava a Teologia da Libertação (TdaL, adiante) à luz da RCC: "De outra parte, uma simples mudança de estrutura política ou econômica não resolveria, se não houvesse primeiramente uma conversão interior". ${ }^{2}$

Ou seja, a cidadania e a dimensão sociopolítica teriam sua via privilegiada através da oração e da conversão humana às doutrinas e valores cristãos. Conforme avalia Gomes - quanto às ações sociais públicas desenvolvidas por grupos ligados à RCC -, as pessoas alvo destas intervenções estariam mais na condição de "objetos de caridade e não sujeito de direitos". ${ }^{3}$ Isto é, uma concepção de campo social e político - e intervenção nele - de estreitas afinidades com concepções políticas e sociais assistencialistas que não questionam o status quo socioeconômico presente na sociedade - e sua estrutura reprodutora e ideológica -, mas apenas busca minorar os efeitos desta estrutura, a mantendo. Ainda segundo Gomes, o "foco está totalmente na dimensão religiosa, no anunciar o 'Senhor Jesus', e especialmente no conhecimento da doutrina católica". ${ }^{4}$ Veremos isto a seguir. Fato é que a RCC, com seu acento na santificação pessoal, faz com que o envolvimento político do cristão carismático não seja visto como algo essencial, mas facultativo. ${ }^{5}$ Salvo quando se trata de salvar a nação de perigos que atentem contra certos valores morais compartilhados pelos membros do movimento, como a seguir também veremos.

\footnotetext{
${ }^{1}$ GOMES, Sandro dos Santos. As novas comunidades católicas: rumo a uma cidadania "renovada"? PUC, Rio de Janeiro, Dissertação de Mestrado em Ciências Sociais, 2008, pp. 92-93.

2 TILLESSE, Caetano Minette de. A Teologia da Libertação à luz da RCC. Loyola, São Paulo: 1978. p. 42.

${ }^{3}$ GOMES, Sandro dos Santos. As novas comunidades católicas: rumo a uma cidadania "renovada"? PUC, Rio de Janeiro, Dissertação de Mestrado em Ciências Sociais, 2008, p. 96.

${ }^{4}$ Idem.

${ }^{5}$ GOMES, Sandro dos Santos. As novas comunidades católicas: rumo a uma cidadania "renovada"? PUC, Rio de Janeiro, Dissertação de Mestrado em Ciências Sociais, 2008, p. 101.
} 


\section{Entre os discursos do dualismo radical e da harmonia ideal}

Haveria, no âmbito do carismatismo católico, alguma dificuldade em absorver certos aspectos da esfera das políticas públicas e socioeconômicas que transcendem às questões matizadas pela religião e pelo discurso religioso, justamente por tais aspectos - em sua transcendência ao discurso e imaginário religioso - estarem em um lastro mais racionalizado, reflexivo e autônomo em relação ao campo explicitamente religioso, o que provocaria dificuldade quando da confrontação deles com concepções do mundo mais encantadas e devedoras de um universo religioso dogmático revelado e inquestionável. Assim, a título de exemplo, já adianto a questão - a ser retomada adiante - sobre a discriminalização do aborto, que para muitos carismáticos não é compreendida no campo de uma discussão plural sobre saúde pública, mas como questão que leva ao céu ou inferno, como revela o comentário de uma internauta que apoiava a homilia de um padre ligado à Comunidade Canção Nova, desestimulando o voto em candidatos e partidos que quisessem refletir sobre o tema da discriminalização do aborto (nomeando o PT, quanto à questão). O padre, na ocasião, disse que poderiam "matá-lo", mas que não se calaria sobre a questão ${ }^{6}$, ao que a internauta comenta, defendendo o padre, de que realmente era melhor morrer por esta verdade que calar-se e ir para o inferno ${ }^{7} \mathrm{Ou}$ seja, quando a dimensão do político - no natural debate e conflituosidade que uma sociedade plural comporta - fica restrita a ser pensada e definida por um imaginário religioso de disputa metafísica entre Deus e o Diabo, céu e inferno, estaríamos, com muita probabilidade, diante não só da desqualificação da reflexão e do debate político enquanto em sua autonomia necessária e diferenciação das esferas, como também de um perigoso viés que tornaria a dimensão política vassala e refém de orientações religiosas, e exclusivistas elas.

Mas, se por um lado o discurso da RCC, quanto ao campo político, pode cair num dualismo soteriológico e agonístico, por outro lado é presente, no discurso e imaginário do movimento, um discurso oposto, de harmonia. $\mathrm{Na}$ RCC, grosso modo, há um discurso interno e geral que, pautado em uma interpretação teológica de que todos são "irmãos" em Cristo e filhos de Deus, anestesiaria a consciência de classe e os conflitos presentes no campo do social e do político. Assim, segundo o discurso nativo, a RCC, em seus

6 Disponível em: <http://oglobo.globo.com/pais/noblat/posts/2010/10/08/pt-tv-cancao-novaentram-em-acordo-331214.asp>. Acesso em 09 de outubro 2010.

7 Disponível em: <http://reporterdecristo.com/inacreditavel-nova-nota-da-cancao-nova-desautorizapublicamente-padre-joseaugusto/>. Acesso em 09 de outubro 2010. 
grupos organizados, "une ricos e pobres, bispos e sacerdotes. (...) Une patrões com empregados e na verdade mostra a variedade e a unidade do Corpo de Cristo". ${ }^{8}$ Tal visão ufano-espiritualista é, de certo modo, transportada para o campo político-social e traduzida nele enquanto omissão da questão de classes na sociedade, no que tange à sua análise para a intervenção política. Monique Hébrard chama a atenção, no âmbito político, para uma concepção profética a permear o discurso da RCC, baseada no amor, e não em análise socioeconômica atenta e crítica. ${ }^{9}$

Provavelmente uma visão ingênua, que não mensura os interesses antagônicos presentes no campo social. Ou uma visão sutilmente ideológica, que encobre tais interesses antagônicos, fazendo do discurso do amor e da fraternidade geral uma manta a suavizar a consciência de classe e dos mecanismos que produzem pobres e ricos, exploradores e explorados? Fica a pergunta. Enfim, cultiva-se o imaginário de um estado de harmonia e paz como superação dos conflitos sociais e econômicos e das divergências de interesses humanos e de grupos, sem que se explicite que tal superação esteja imbricada em campo de conflitos, particularmente representado nos conflitos e jogos políticos. Há mesmo um mal estar com a idéia do conflito social. ${ }^{10}$ Contudo penso que, embora o discurso oficial possa assim se articular, a prática - particularmente em tempos de eleição, como demonstrado no pleito de 2010 - contradiga este discurso, dado que em tal ocasião muitos grupos ligados à RCC desenvolveram discurso explicitamente hostil à candidata do PT, supostamente por questões em torno de valores bioéticos tornados centrais para uma valoração da qualidade das candidaturas.

\section{A voz oficial}

Em meio a estes dois discursos - o da harmonia ideal e o do dualismo radical - a RCC, enquanto estrutura institucional na Igreja Católica Apostólica Romana no Brasil, mantém um órgão específico para tratar da dimensão política da sociedade. Assim, a RCC nacional comporta um "ministério" específico

\footnotetext{
${ }^{8}$ ALDAY, Salvador. Carismático - a presença jubilosa do Espírito Santo no mundo actual. Editorial Missões, Cucujães, 1994, p. 47. Apud COSTA, Joaquim. Sociologia dos novos movimentos eclesiais: focolares, carismáticos e neocatecumenais em Braga. Afrontamento, Porto, 2006, p. 140. ${ }^{9}$ HÉBRARD, Monique. Os carismáticos. Editorial Perpétuo Socorro, Porto, 1992, pp. 75-80.

${ }^{10}$ GOMES, Sandro dos Santos. As novas comunidades católicas: rumo a uma cidadania "renovada"? PUC, Rio de Janeiro, Dissertação de Mestrado em Ciências Sociais, 2008, p. 95.
} 
para orientar católicos na questão da correlação entre fé e política, o Ministério Fé e Política (antiga secretaria Matias). Portanto, apesar de uma concepção de análise tradicional (e já em desuso) no mundo acadêmico (às vezes sob influxo da tradição da Teologia da Libertação - TdaL) de que a RCC despolitizaria as dimensões sociais da fé, inculcando um imaginário religioso alienado e desprovido de significações políticas interventivas e ativas, a RCC explicita sim, em nível oficial do Movimento, preocupação política. Aliás, justamente a idéia de que a RCC seja um movimento substancialmente "espiritualista", sem conotações ou preocupações políticas, faz com que ela possa agir de forma livre no campo político sem agudo controle da hierarquia. ${ }^{11}$

Enquanto que, tradicionalmente, a dimensão política em grupos católicos geridos pela inspiração da TdaL se dá a partir das bases e, a partir delas, toma visibilidade em intervenções reivindicativas e político-partidárias, na RCC o gerir da relação fé/política tem seu canal oficial no topo, institucional, na administração burocrática do movimento, e a partir de lá desce às bases. Portanto, em princípio, não é de geração orgânica, fruto de reflexão entre fé e sociedade, nas bases. Esta estrutura burocrática busca veicular um discurso que visibiliza temas tradicionais (em ótica mais à direita teológica), no sentido de formatar as relações entre fé e política nas bases da RCC. Como descreve o próprio Ministério, sobre seus objetivos: “O Ministério Fé e Política é o serviço dentro da Renovação Carismática Católica para a evangelização da política, a partir da experiência do batismo no Espírito Santo"12. Ora, esta apresentação nos diz muito. A relação fé/política é concebida como um exercício de "evangelização da política", de formatação do cenário e da prática política a partir da fé. A política, nesta relação, pode ser comparada a um objeto, e a fé à dimensão dinâmica e tuteladora deste objeto. Prescreve-se uma ação interventiva sobre o político a adaptar-se a postulados de fé.

Mas que fé? Católica, diria-se. Mas que catolicismo? Agora o diferencial: fé "a partir da experiência do batismo no Espírito Santo". Portanto, não a fé que parte de uma leitura popular da Bíblia, por exemplo. É a fé pentecostal católica. Uma fé de renascidos por um batismo especial, diferenciada, por suposto, da fé daqueles que não experimentaram tal batismo. Aí seu especifico. E isto faz uma grande diferença, pois tal fé costuma - dentro da teologia

${ }^{11}$ CARRANZA, Brenda. Renovação Carismática Católica: origens, mudanças e tendências. Santuário, Aparecida, 2000, p. 159.

${ }^{12}$ Disponível em: <http://www.rccbrasil.org.br/ministerio-de-fe-e-politica.php $>$. Acesso em 02 de outubro de 2010 . 
carismático-pentecostal católica - privilegiar temas como "batalha espiritual", Diabo, e, a partir daí, uma pregação e consciência religiosa que lida com um imaginário de que em várias instâncias da vida - desde a pessoal até a sociopolítica - está a se travar uma luta de projetos entre o bem e o mal, entre Deus e o Diabo. E o Diabo, segundo este imaginário carismático popular (?), gerenciaria suas estratégias de tomada de almas, cidades, países, mundo, através de canais históricos empíricos, dentre eles, no campo político, possíveis partidos e candidatos. Ora, sem este imaginário religioso a permear alguns grupos e indivíduos carismáticos, não é possível, penso eu, entender o que ocorreu no pleito presidencial de 2010, por exemplo, quanto à desqualificação do PT e de sua candidata, feita por parte de algumas vozes religiosas. Desqualificação que teria, portanto, questões de fundo "metafísico" a determiná-la.

Voltando ao documento do Ministério Fé e Política, ele prossegue dizendo que a intenção é a de "evangelizar, formar e exortar a RCC a participar, com coragem e discernimento, da atividade políticas para gravar a lei divina na cidade terrestre" ${ }^{13}$. O que é confirmado por lideranças nas bases, que enfatizam que "antes e acima de tudo, o projeto da RCC será um projeto religioso, jamais político e nem mesmo social. O objetivo único e principal é evangelizar". ${ }^{14}$ Portanto, não se concebe a relação entre fé e política enquanto criadora e beneficiadora de um projeto plural, includente, sensível à alteridade. Parte-se da concepção platônico-agostiniana das duas cidades, e de que a sociedade celeste deve ditar e editar a cidade terrestre, cravando nela sua lei. A separação entre Estado e Religião é atenuada e comprometida: à religião caberia conduzir, no aspecto ético-legal, o Estado, formatando-o. Aliás, esta é uma das distinções mais visíveis em relação à concepção política gestada ou inspirada na TdaL: enquanto na perspectiva da TdaL os temas de reflexão e intervenção política, prioritariamente, fazem referência à transformação do modelo econômico e social, levantando bandeiras como as da Reforma Agrária, organização e luta dos trabalhadores, idealização de um Estado forte e social, a RCC figura bandeiras que, grosso modo, ignoram a dimensão explicitamente socioeconômica da política, fixando suas lutas em questões de consolidação do espaço de influência católica e em assuntos de teor ético referenciados em posições teológicas tradicionais da Igreja: bioética,

13 Disponível em: <http://www.rccbrasil.org.br/download/RESOLUCAO_RCC_2010_ENF. pdf $>$. Acesso em 02 de outubro de 2010.

${ }^{14}$ SOUSA, Ronaldo José de. Ide às encruzilhadas: Doutrina Social, Renovação Carismática e opção pelos pobres. Santuário, Aparecida, 2003, p. 69. 
educação católica, questões sobre direitos reprodutivos, etc. Enfim, produções políticas centralizadas nas áreas de educação e saúde que visam a preservação de um determinado ethos católico tradicional, enquanto a produção da TdaL baliza-se, preferencialmente, em temas referentes à estrutura econômica, renda e modelo de gestão social. Em outras palavras, o viés político da RCC buscaria a recomposição do religioso (e de sua esfera de influência) na sociedade/política secularizada.

De certa forma, não enfatizando temas adotados pela vertente mais à esquerda na Igreja, a RCC produziria um discurso político inócuo quanto à transformação de estruturas sociais, focando ele, o discurso, temas pontuais que não influem - em grandeza - nas relações socioeconômicas. Aliás, a produção da relação fé/política focada na reflexão e intervenção sobre o campo socioeconômico é sentida, por muitos na RCC, como aliada ou perigosamente vizinha de concepções marxistas, e talvez por isso mesmo pouco acentuada. Contudo, talvez a RCC, de forma institucional ou em muitos de seus grupos e indivíduos, não reflita - ou prefira não refletir - que a falta de intervenção ou de oferta de modelos alternativos para o campo socioeconômico possa ser a sustentação, por omissão ou de forma consciente, de um modelo econômico, capitalista e neoliberal, que foi e é, reiteradas vezes, criticado pela CNBB e mesmo pelo Vaticano.

\section{A RCC, a política partidária e a inserção nas instituições políticas}

A socióloga Brenda Carranza aponta para um compromisso histórico mais conservador na atuação política da RCC. Segundo ela, já em seu arrebol, no início da década de 70 do século passado, a RCC se articulava para ocupar espaço - e cargos - na política nacional e local. ${ }^{15}$ Segundo a autora, um dos principais artífices da vinculação entre fé e política, na RCC, foi o Pe. Eduardo Dougherty (missionário jesuíta norte-americano e fundador da Associação do Senhor Jesus), cuja preocupação era fazer do Brasil um país cristão (qual modelo?). Ou seja, uma plataforma religiosa e confessional para a sociedade civil e plural. Um dos primeiros a terem seu apoio, e a alcançar sucesso político, foi Salvador Zimbaldi, eleito vereador em Campinas, em 1982, e depois eleito para outros cargos nas eleições posteriores. Atualmente no PDT, foi reeleito, no pleito de 2010, para deputado federal (SP), com lastro eleitoral em comunidades e grupos carismáticos, sob o lema "um voto de fé, pela vida e

${ }^{15}$ CARRANZA, Brenda. Renovação Carismática Católica: origens, mudanças e tendências. Santuário, Aparecida, 2000. p. 157. 
pela família". ${ }^{16}$ Em seu logo de campanha, havia a imagem, estilizada, de uma pomba, possível referência ao Espírito Santo.

Há muitos outros parlamentares e líderes políticos com origem - ou representação explícita - na RCC e que militam em partidos políticos os mais diversos, inclusive naqueles considerados, tradicionalmente, mais à esquerda, como o emblemático caso do deputado Alessandro Molon, do PT fluminense (eleito deputado federal em 2010). Isto mostra que não cabe, para a RCC e sua dimensão política, uma análise simplista e reducionista de que o movimento apenas abrigaria tendências conservadoras na política. Contudo, mesmo os mais à esquerda, se ligados (ou mesmo sustentados, em seus mandatos) à RCC, provavelmente encampam as tendências mais à direita do movimento quanto às questões bioéticas e reprodutivas, dentre outras que permeiam o campo da moral.

Até as eleições de 1996 os carismáticos se candidatavam por diferentes partidos (com mais freqüência o PSDB). A partir de 1997 o PSN passa a agregar, de forma mais substancial, as candidaturas com inspiração na RCC. ${ }^{17}$ O PSN (Partido Solidarista Nacional) teve seu registro em 1995, e alguns de seus membros eram ligados a grupos da RCC, intentando, com a fundação deste partido, oferecer à sociedade a opção de uma agremiação política de inspiração cristã. O PSN teve vida breve, diluindo-se, em 2000, no atual PHS (Partido Humanista da Solidariedade), que tem explícita inspiração cristã, mas sem ser devedor de nenhum movimento eclesial específico. Atualmente não há, por parte da RCC, uma orientação oficial quanto à filiação partidária de seus membros ou lançamento de candidaturas. Segundo Miranda, a RCC, contudo, contou com um candidato para presidente - oficioso - nas eleições de 1998: o deputado federal pela Bahia, e octagenário, Vasco Neto, professor aposentado da UFBA. Conforme a configuração da candidatura, era ela um protesto simbólico, a questionar a polaridade entre comunismo e capitalismo..$^{18}$

Embora não haja articulações explicitamente planejadas no campo político-partidário (ao menos segundo a postura e o discurso oficial da RCC), Carranza afirma que há esquemas estratégicos de formação de quadros, dentre as lideranças

\footnotetext{
${ }^{16}$ Neste lema me parece resumida a orientação política da RCC: fazer com que a fé católica (seus valores e hegemonia) seja defendida no campo político; preservar e consolidar um modelo de família tradicional pontuado por esta fé; lutar pela vida no que concerne a certas concepções bioéticas.

${ }^{17}$ MIRANDA, Júlia. Carisma, sociedade e política: novas linguagens do religioso e do político. Relume Dumará, Rio de Janeiro, 1999, p. 97.

${ }^{18}$ MIRANDA, Júlia. Carisma, sociedade e política: novas linguagens do religioso e do político. Relume Dumará, Rio de Janeiro, 1999, p. 98.
} 
da RCC, para ocupar cargos eletivos em nome da RCC. ${ }^{19}$ Haveria o projeto, articulado ou espontâneo, de formar blocos no Congresso e Senado, por exemplo, blocos que visariam impedir projetos de lei que revisem questões de orientação sexual (união civil entre parceiros do mesmo sexo), reprodutivas (aborto) e de hegemonia educacional cristã (ensino religioso confessional, defesa de prerrogativas do ensino particular, etc). Nesta articulação prática em alavancar candidaturas de candidatos com origem ou representação na RCC, alguns grupos de oração constituem-se, em época de eleição, cabos eleitorais de candidatos católicos, com ou sem ligação à RCC. Os grupos de oração na base são mais abertos à atuação sociopolítica do que a RCC enquanto instituição oficial, pois sofrem menos a formalidade do discurso "prudente" do institucional. ${ }^{20}$

Conquanto para a maioria dos carismáticos a dimensão política - lato sensu - seja de desinteresse, particularmente a articulação política/religião, as pesquisas de Júlia Miranda referentes à relação religião/política apontam que, para os carismáticos, a dimensão política é representada, acentuadamente, pelo "tempo da política", o período eleitoral e a questão partidária nele. ${ }^{21}$ Portanto, a reflexão fé/política é geralmente pontual, ligada a momentos políticos, mas efetiva neles. Assim, no período eleitoral os candidatos com origem na RCC buscariam construir suas candidaturas com base em sua pertença religiosa. ${ }^{22}$ Candidatos ligados à RCC visitam grupos de oração, Seminários de Vida no Espírito Santo, etc, inclusive, muitas vezes, se visibilizando nestes locais através de palestras e cursos. ${ }^{23}$ Orações de

${ }^{19}$ CARRANZA, Brenda. Renovação Carismática Católica: origens, mudanças e tendências. Santuário, Aparecida, 2000, p. 163.

${ }^{20}$ OLIVEIRA, Pedro Ribeiro de. CEBs, carismáticos católicos e transformação social. In SOTER (Org.). Religião e transformação social no Brasil hoje. Paulinas, São Paulo, 2007, pp. 11-24 (24). Acima eu havia pontuado que a questão oficial da relação fé/política era representada a partir da estrutura burocrática do movimento. Isto, é preciso que fique claro, no aspecto de que a estrutura alimenta e municia os grupos carismáticos quanto aos temas básicos de consciência política na RCC (geralmente na esfera da moral e da bioética, dos valores católicos ditos tradicionais, como já vimos). Ora, a base (os grupos de oração), absorve este discurso e imaginário religioso, e, sendo o núcleo basilar do edifício da RCC, conjuga o discurso oficial à prática de difundir certas idéias-força no campo político/religioso e de intervir de forma prática neste campo, apoiando candidatos próximos a grupos de oração ou selecionados como afins deles e de seus ideários.

${ }^{21}$ MIRANDA, Júlia. Carisma, sociedade e política: novas linguagens do religioso e do político. Relume Dumará, Rio de Janeiro, 1999, p. 98.

${ }_{22}^{2}$ MIRANDA, Júlia. Carisma, sociedade e política: novas linguagens do religioso e do político. Relume Dumará, Rio de Janeiro, 1999, p. 99.

${ }^{23}$ MIRANDA, Júlia. Carisma, sociedade e política: novas linguagens do religioso e do político. 
bênção e consagração do candidato (feitas por membros e grupos da RCC) teriam lugar em certos circuitos da $\mathrm{RCC}$, fortalecendo um imaginário de legitimação divina e vocacional do mesmo, conferindo a esfera do sagrado ao campo secular.

A motivação puramente racional para a atuação política da e na RCC seria, de certa forma, subsumida por uma motivação de fundo vocacional, com sentido religioso a predominar. Ou seja, a intervenção no campo sociopolítico não teria por base - no mínimo na questão motivacional - os princípios reguladores da racionalidade que separam os domínios do secular e do religioso, do público e do privado em sua acepção moderna, mas estaria previamente comprometida, esta participação e intervenção política, por um caráter de experiência de conversão religiosa que dá um sentido para a atuação na política a partir e por causa desta experiência. Assim, pode-se presumir que muito da motivação sociopolítica na RCC, entre seus indivíduos, provenha de compromissos oriundos do plano da transcendência ("missões", "chamados", etc) ${ }^{24}$. Até aí, RCC e TdaL têm, de certa forma, pontos em comum. A questão e a diferenciação entre elas - é em como isto se articula, na prática, no campo sociopolítico. No caso da RCC, que aqui nos interessa, a prática política se traduz, como já vimos, na defesa de certas bandeiras morais tradicionais, como forma de intervenção para se sustentar a hegemonia de certos valores católicos na sociedade, e na articulação para eleger líderes católicos ligados a esta visão moral a ser defendida. Claro, a questão econômica e estrutural é também um ponto da visão político-social da RCC, mas adjacente, e gerido por ideário talvez reformista.

\section{O leitmotiv do atual rosto político na $\mathrm{RCC}$}

Existiria uma plataforma política específica que mobilizasse fortemente a RCC em relação à sua reflexão e atuação política? Como em vários momentos já pontuado acima, ela existe. A questão confessional dá o norte da reflexão e atuação política na RCC, ao contrário das CEBs e TdaL, cujas preocupações não giram, necessariamente, em torno de uma afirmação confessional-doutrinária para a sociedade, mas se pautam em projetos que transcendem a questão

Relume Dumará, Rio de Janeiro, 1999, p. 108.

${ }^{24}$ CAMURÇA, Marcelo. Seria a caridade a "religião civil" dos brasileiros? In Praia Vermelha (UFRJ), Rio de Janeiro, n. 12, 2005. p. 47. Embora Camurça não se refira, neste texto, especificamente aos carismáticos, interpreto que a análise a eles também cabe. 
religiosa em si, como, por exemplo, demarcação de terras indígenas, reforma agrária e redistribuição de renda. Com seu discurso político atrelado e tutelado pela agenda confessional, a RCC demonstra um "não reconhecimento da autonomia da esfera política e religiosa, conquista da modernidade". ${ }^{25}$ Talvez não seja demasiado dizer que a RCC, na conjugação da pauta fé/política, ensaia retorno a uma era em que, de forma oficial ou oficiosa, a Igreja era a eminência parda do poder político e de suas definições para o campo do social.

A TdaL veicula, em seu discurso, a noção de pecado estrutural, apontando que a estrutura socioeconômica vigente é cruel e injusta. A RCC, no entanto, olvida em boa parte tal discurso, ao menos assim como ele é feito pela TdaL, concentrando sua visão - e ação - sobre o social na questão do pecado moral pessoal (conforme determinado entendimento dele por uma teologia mais conservadora), o vinculado às questões referentes ao corpo, gênero e sexualidade. Assim, "qualquer mudança social é sempre concebida como projeto de moralização, de uma moral do indivíduo, do sexo e das relações mais internas da vida familiar". ${ }^{26} \mathrm{O}$ direito à vida é entendido substancialmente (e exclusivamente?) como direito a nascer e normatização dos direitos civis quanto à união matrimonial entre homem e mulher, conquanto a TdaL tem enfatizado o direito à vida de forma lato, como direito a justo salário, emprego, condições dignas de vida, acesso universal, gratuito e de qualidade à saúde, educação e cultura. Grosso modo, poderíamos afirmar que a visão do direito à vida, na RCC, se restringe ao micro (instância do núcleo familiar e do direito, ou não, de pessoas decidirem sobre seus corpos e sexualidade), enquanto que a visão da TdaL, no tocante ao direito à vida, tem abrangência macro (as estruturas sociais que proporcionam, ou não, dignidade no viver).

\section{Considerações finais}

O presente texto teve como objetivo pontuar, de forma provisória e parcial, alguns pontos-chaves para se compreender as dimensões políticas imbricadas sob o grande toldo da RCC. Certamente muitos aspectos ficaram ausentes, devido à brevidade do texto aqui proposto. A intenção central desta reflexão, no entanto, foi visibilizar um pouco do chão que sustenta e no qual se move a visão política na RCC. Assim, destaco a questão da participação e intervenção na política como

${ }^{25}$ CARRANZA, Brenda. Renovação Carismática Católica: origens, mudanças e tendências. Santuário, Aparecida, 2000, p. 168.

${ }^{26}$ PRANDI, Reginaldo. Um sopro do Espírito. Edusp, São Paulo, 1997, p. 171. 
exercício de evangelização e de um projeto religioso para a sociedade como mote oficial desta relação da RCC com a política. Isto é, a visão doutrinária e espiritualista definiria os contornos não só da ação política na RCC, como a própria visão de como deve ser a sociedade, refletindo para ela um projeto não necessariamente plural, mas de conotações confessionais - e, talvez, hegemônicas - de uma determinada fé e moral a balizá-la. Nisto a RCC teria, por exemplo, alguma afinidade eletiva com a TdaL: transformar a sociedade no espelho do - ou no próprio - reino de Deus. As concepções das características deste reino descido à sociedade é que divergem substancialmente entre as duas tendências teológicas aqui nomeadas. Assim também como os meios para se chegar à sua consecução.

Neste ideário para o campo político influiriam - para boa parte dos carismáticos - imaginários metafísicos de grande poder simbólico, que fazem com que o campo empírico da sociedade e da política seja visto como encampado e articulado por lutas urânicas, de fundo soteriológico e agonístico. Ou seja, em última instância não são projetos sociais e econômicos a serem discutidos de forma plural e racional que estão em jogo; mas, por trás deles, são projetos "espirituais" que determinam estes projetos empíricos. Isto é, o encantamento da dimensão política e o enfraquecimento de sua dimensão secular e racional, ou o seqüestro destas dimensões para articulá-las a serviço do imaginário religioso e de seus interesses.

Enfim, parece ficar claro, também, que, ainda que haja - grosso modo - um modelo socioeconômico mais conservador afeito à preservação pela maioria daqueles que se filiam ao ideário carismático, o carro-chefe de sua manutenção não se dá - ao menos neste momento histórico -, por um discurso explicito de sua defesa, mas por um discurso que veicula como central temas da moral tradicional católica. É por meio deste discurso que se tem desqualificado alternativas políticas de um modelo social mais plural, inclusivo e reflexivo.

$\mathrm{Na}$ discussão sempre renhida e disputada a respeito das dimensões da secularização ou não da sociedade brasileira, os movimentos carismáticos e pentecostais, católicos ou evangélicos, ganham um capítulo importante. E o último pleito eleitoral de 2010 veio a mostrar que este capítulo se alarga e ganha maior importância nesta reflexão. As cenas dos próximos capítulos ainda terão muito a mostrar sobre como a religião, e o carismatismo e pentecostalismo em particular, definirão os contornos da relação fé/política e, consequentemente, da secularização no Brasil. 


\section{Referências Bibliográficas}

ALDAY, Salvador. Carismático - a presença jubilosa do Espírito Santo no mundo actual. Editorial Missões, Cucujães, 1994.

CAMURÇA, Marcelo. Seria a caridade a "religião civil" dos brasileiros? In Praia Vermelha (UFRJ), Rio de Janeiro, n. 12, 2005.

CARRANZA, Brenda. Renovação Carismática Católica: origens, mudanças e tendências. Santuário, Aparecida, 2000.

COSTA, Joaquim. Sociologia dos novos movimentos eclesiais: focolares, carismáticos e neocatecumenais em Braga. Afrontamento, Porto, 2006.

GOMES, Sandro dos Santos. As novas comunidades católicas: rumo a uma cidadania "renovada"?. PUC, Rio de Janeiro, Dissertação de Mestrado em Ciências Sociais, 2008.

HÉBRARD, Monique. Os carismáticos. Editorial Perpétuo Socorro, Porto, 1992.

MIRANDA, Júlia. Carisma, sociedade e política: novas linguagens do religioso e do politico. Relume Dumará, Rio de Janeiro, 1999.

OLIVEIRA, Pedro Ribeiro de. CEBs, carismáticos católicos e transformação social. In SOTER (Org.). Religião e transformação social no Brasil hoje. Paulinas, São Paulo, 2007, pp. 11-24.

PRANDI, Reginaldo. Um sopro do Espirito. Edusp, São Paulo, 1997.

SOUSA, Ronaldo José de. Ide às encruzilhadas: Doutrina Social, Renovação Carismática e opção pelos pobres. Santuário, Aparecida, 2003.

TILlESSE, Caetano Minette de. A Teologia da Libertação à luz da RCC. Loyola, São Paulo: 1978.

\section{Rodrigo Portella}

Doutor em Ciência da Religião pela UFJF. Professor Adjunto no Departamento de Ciência da Religião da UFJF. Coordenador da Coleção "Cultura \& Religião", da Editora Santuário.

Artigo Recebido em 23/08/2011

Artigo Aprovado em 28/11/2011 